\title{
THE SEMIOTICS ANALYSIS ON THE ENVIRONMENT IN “THE JOURNEY TO ATLANTIS" PICTURE BOOK
}

\author{
Darsita Suparno ${ }^{1}$, Laksmy Ady Kusumoriny², \\ Universitas Islam Negeri Syarif Hidayatullah Jakarta ${ }^{1}$ \\ Universitas Pamulang ${ }^{2}$ \\ galuhdarsita@gmail.com
}

\begin{abstract}
This study aimed (1) to describe the semiotic process of environment symbols in The Journey to Atlantis, (2)to generate the meaning of identified symbols which are shown through verbal and non-verbal contained in The Journey to Atlantis. This is a descriptive qualitative study trying to identify and analyze semiosis process of environment symbols, and describe the found verbal and nonverbal symbols in Elisabetta Dami's The Journey to Atlantis Picture Book using semiotic theory by Charles Sanders Peirce (1991). The data for the finding and analysis were taken from Elisabetta Dami'sThe Journey to Atlantis (2012) Picture Book. The study shows that there are 40 icons in form of words and 36 onomatopoeia as verbal symbols, and 40 picture decribe Atlantis environment and 18 color as nonverbal symbols which are related to the environment.
\end{abstract}

Keywords: Semiotics, verbal and nonverbal symbols, Elisabetta Dami's The Journey to Atlantis Picture Book, Peirce's theory

\section{INTRODUCTION}

The knowledge of the environment in picture books is important for an understanding of word or text. Many picture books consist of language, visual image such as photographs and forms of illustration. It is useful to strengthen visual thinking skills and introduce complex concepts in a safe environment. Language and image, which are sign or symbol, make young reader or children, kid identify themselves to understand every aspect of life easily. In other word, language and drawing itself is involved of sign that is studied in semiotics. Besides that, in this millennium society era one specifically challenging that children might counter when learning and coming into environment in real-world information from picture books is that socalled symbolic insight. Pictures in picture books are made based on the imagination of the author. Those pictures can enrich the emotional, cognitive, affective, and language skills of children. According to Kraayenoord \& Paris (1996), experience significant in order for children to make contextual meaning from pictures in books. Activities such as reading or telling stories for children can help children in understanding the world where they are realistic and original (Pearson, 1993).

This experience has a crucial role in developing creative thinking skills, developing new meanings together with other children. Besides, they contribute to the culture in which they learn about the cultural environment. Those conditions are purposed to convey the meaning, message, to form of concept, idea, theme of environment which are made and transmitted through the interaction words as verbal symbol and picture as nonverbal symbols. Readers get the meaning of environment idea from the relationship between text and drawing. The content 
story also reflects everyday life, such nature of environment and it can develop children's knowledge by offering new narrative experience as explained by Bianquin \& Sacchi (2017). In brief, a picture book could influence the children's view of an environment. The picture books which read by many children everywhere, sometimes give difficult or improper image to the children as readers, and because of that it can cause thoughtful problem to children, parents, family even society In brief, it is the most effective way to communicate both cultural message, society and nature of environment values to children. Recently, researchers have shown an increased interest in understanding a picture book, semiotics has applied, due to assume, that picture books have numerous signs environment.

Corresponding to the background of the study of the environment symbols, the question of the study is formulated such as follow: how are the semiosis process of environment symbols, and how are the meanings of these symbols which are shown through verbal and non-verbal in The Journey to Atlantis? The aim of this paper is to describe the semiosis process of environment symbols and to generate the meaning of identified symbols which are shown through verbal and non-verbal contained in The Journey to Atlantis,(Damy 2012).The findings of this study will help the writer to enhance the writer's knowledge in interpreting the meanings of the symbols which are shown through verbal (word, onomatopoeia) together with non-verbal (picture and color) by using Peirce theory. For readers to add information that the illustrations of verbal and non-verbal symbols in a picture book helps children understand what they are reading and allow young readers to analyze the story.

\section{REVIEW OF LITERATURE}

There have been several studies in the children literature reporting such as (Ozsezer and Canbazoglu 2018), (Callow 2018), (Yu and Song 2017), (Mushodiq 2018). The aim of (Ozsezer and Canbazoglu 2018) study is to collect and do critical analysis to children's comments on the pictures in their story books. There are four first-grade students of a public primary school in Adana participating in the study. The research model is used as an example of phenomenology amongst qualitative research patterns. Furthermore, focus group method was deployed as the tool in collecting data collection as well as observation method deployed during their second exercise to crosscheck the first method. To analyze the result of the data, descriptive and document analysis methods were employed. This study tried to seek a finding from students' comments on the pictures consisting of four different themes. "Description" among these themes was the most common in student expressions. The sentences existed in the themes of superficial interpretation, critical understanding and imaginative interpretation were less frequently used by the students. The number of words students used to describe the picture is another finding. Students were assigned to build short sentences consisting of 2-3 words. Thus, Callow (2018) presents findings from a study that investigates strategies in assessing primary students' comprehension of written and visual text in picture books. The data were drawn from a large pilot study in an urban setting of a large Australian city. It engages 40 students over 4 grade stages from Foundation to Year 6. This article specifically focuses on 7 students in the first year of school or so-called Foundation. This study discussed, observed, questioned and drew activities based on a common picture book for each grade. The assessment tasks which were undertaken as individual interview were analyzed using functional semiotics and multimodal theory. It included a focus on visual meta-language. Then, the findings are presented and elaborated to the extent of the effectiveness of both the questions and assessment strategies, the application for classroom use to support teachers to assess their students' multimodal ability, and interpretations of children's responses.

$\mathrm{Yu}$ \& Song (2017) reveal the congruency of cover pictures and verbal texts in demonstrating the Zen master Huineng in two English translations of the Platform Sutra. It focuses on the analytical tools and interpersonal meanings adopted using systemic functional linguistics as well as visual social semiotics theory of Kress \& van Leeuwen's. It found that the 
visual techniques used to portray Huineng on the book covers are evidently consistent with the verbal choices deployed to show Huineng in the translated texts. On the other hand, the medium to eye-level angle complement and close shot use the choice of speakerplus "we" as the most frequently appeared interactive subject person, and polite commands and qualified statements in Wong's translation, the very long shot is suitable with the use of "I" and addressee "you", as well as direct and categorical commands in Cleary's translation. Accordingly, Mushodiq (2018) examines a short story written by Naguib Mahfouz with the title 'IndamaYa'ti al-Masa. It tells about the life of a couple of husband wives in old age who has filled with complex family conflicts. Researchers consider that the short story contains a lot of signs that must be studied its meaning. old age, bearing in mind there are similarities between the two. This study focuses on objects consisting of iconic signs, indexes, and symbols. Then, researchers used the sign theory formulated by Charles Sanders Peirce. Peirce considers that the sign is built on triadic elements, namely, representamen, objects, and interpretants. By using the Peircean signs, these studies found are old indexes, old symbols, conflict, metaphorical icons. The finding is consistent with findings of past studies by Yu \& Song (2017) and Mushodiq (2018), which is consistent with the verbal choices and focuses on objects consisting of iconic signs, indexes, and symbols. The similarities with present study are such as the focuses one verbal text and the object such indexes, icons and symbols and the Peirce semiotics perspective. The differences with current study are the title of picture book, and the aim of the study.

\section{Underlying theories}

The purpose of this literature review is to provide some indication of the scope of semiotics. Semiotics is the study of sign. Sign refers to anything stands for something else such as: words, images, sounds, gestures, colors, and objects as argued by Chandler (2006). Semiotics study in sign system medium or genre, it is focus on several aspects such as: how reality is represented, how meanings are made.. These two aspects are identified as mental process as mentioned by Chandler (2006). Semiology is a branch of linguistics as describes by Roland Barthes as cited by Chandler (2006). Related to this point of view language is the central and most important among all human semiotics systems. In short, the founder of the modern theory of sign will describe such as follow:

\section{Ferdinand de Saussure}

Hidayat (1988) explained that Saussure (1857) begins his popular theory of sign by identifying sign that express idea from a language system, and compare it to a writing system such as symbolic rites, alphabet, military signal, polite formula and many more. A science that studies the life of sign within society is credible for Saussure thought. The element of sign by Saussure separates the object of language between significant (signifier: material aspect of a language) and signifie (signified: mental aspect of). Significant can be a form of language. Signifie is a mental aspect of language appears in human though. Significant and the signifie are principally arbiter.

\section{Charles Sanders Peirce}

A sign is defined by Peirce in Buchler (2006) as "the quasi-necessary, or formal doctrine of signs. A sign or representamen stands to somebody for something in some respect or capacity. It addresses somebody that creates the mind of that person an equivalent sign or a more development sign. Peirce also describes that sign which it creates, he calls the first sign's interpretant. The sign stands for something that is its object. Not in all respects, the sign stands for that object and is about a sort of idea. It has called the ground of the representamen. Further, Peirce explained that a sign or representamen stands in such genuine triadic. It is related to a second, namely, Object. The third is the interpretant. It stands to the same Object as cited.

Based on this information, explaining about Peirce's semiotics theory, this work uses the 
secondary sources. It takes references dealing with the theory of Peirce's works. The three element relationship consist of a Sign, or representamen. It is the first element that exists in such a genuine triadic relation to the second element called Object. Object is capable to determine the third element. The thir element, called Interpretant, assume the same triadic relation to its Object. Many authors further extend Peirce's ideas of his triadic model of semiotics. According to Buchler (2006) \& Nöth (2011), Peirce maps signs into three. They are qualisign, sinsign, and legisign.

Qualisign refers to a quality in the sign. It cannot perform as a sign until it is formed. It can be the loud and the sweet voice. Sinsign refers to an actual event with a sign. A girl who screams is meant as she is getting hurt of probably is in a dangerous situation. Legisign, on the other hand, refers to a law that is in a sign. It is usually delivered by men. The example is traffic lights.

Peirce in Buchler (2006) states that its object is a sign that may be classified as an index, an icon, or a symbol. Icon refers to a sign that refers to the object. The object denotes merely by virtue of characters of its own. Index refers to a sign which refers to the Object. The object is denoted by virtue of being really affected by that Object. Symbol refers to a sign which refers to the object. The object is denoted by virtue of a law, usually an association of general ideas, which operates to cause the Symbol to be interpreted as referring to that object.

\section{METHOD}

\section{Approach of the Study}

The writer uses the Qualitative Approach to analyze: the semiosis process of environment symbols; the meaning of these symbols which are shown through verbal and non-verbal in "The Journey to Atlantis." It means that the data are verbal and non-verbal text used by the characters collected by reading the picture book, and these data are a part of qualitative data as they are in word forms. Besides, they are identified based on the concept of symbol as one of the phenomena occur in communication.

\section{Data Source}

Primary data Primary data refers to the first hand data gathered by researcher himself, the data always specific to the researchers needs, as argued by (Ajayi 2017). In this study primary data are obtained from picture book the title is "The Journey to Atlantis", through observation. While secondary data means data collected by someone else earlier. The sources are obtained from books, journals, and articles, these secondary data may or may not be specific to the researcher's need, as described by (Ajayi 2017).

\section{Data Collection}

Data in this study were collected from "The Journey to Atlantis" by focusing on the text, picture and color that were gathered in some steps such as follow: the picture book with the title "The Journey to Atlantis" is consisted twelve chapters. Every chapter is read repeatedly for three times to get deep understand the content of the story; identifying the title of every chapter in the whole story; marking the text, especially the sentences, phrases, words, onomatopoeia which contains the verbal symbol-meaning, and marking the pictures; categorizing these verbal and non-verbal symbols into appropriate meaning.

\section{Method of Data Analysis}

The data that have been collected, first are classified into the types of symbols. Then they are identified based on their context and are classified into verbal text or non-verbal text. (Peirce 1991) semiotic triangle theory is used in analyzing data verbal symbol. (Pettersson 2000) visual symbol or iconographic theory is used to analyze picture, and (Calero 2005) color theory is used in analyzing data picture colors. These three theories are assumed to be related to each 
other for the following reasons: picture book is a source that consists of morphological and functional features. They consist of design skills, written and illustrated languages, visual symbol, energies that together contribute to the production of a physical object, and metaphors and visions of the world Bianquin \& Sacchi (2017). It also refers to books containing both texts and illustrations. These two are altogether to tell a story. It represents objects and environments, or color concepts and exposed shape (Bianquin and Sacchi 2017).

\section{FINDINGS AND DISCUSSION}

\section{Analyzing the Semiosis process of environment and the meaning of symbol Found in "The Journey to Atlantis" A Picture Book"}

Overall, there are forty pictures found. Instead of analyzing those all, the writer selected only 8 pictures to analyze. The selected images are directed to sequence number data called data number 1-8. The data are discussed to figure out what signs were shown in the Elisabetta Dami picture book as well as what all the signs are. The data were analyzed by using Peirce's sign theory.

Peirce (in Liszka, 2012) states that sign refers to all thoughts and knowledge that can only be manifested in signs. Furthermore, semiotics similarly shows that a sign is able to be manifested. It can be picture, sound, thought, action, feeling, or naturally occurring event, still the formal conditions which make a sign that would present. Based on this, indexes, icons, and symbols are discussed intentionally. The author believes that these sampled data represent the whole data based on what the writer presented earlier. The data were analyzed using Trichotomy concept of Peirce's theory. It can be visualized in the triangle shown by Figure 1.

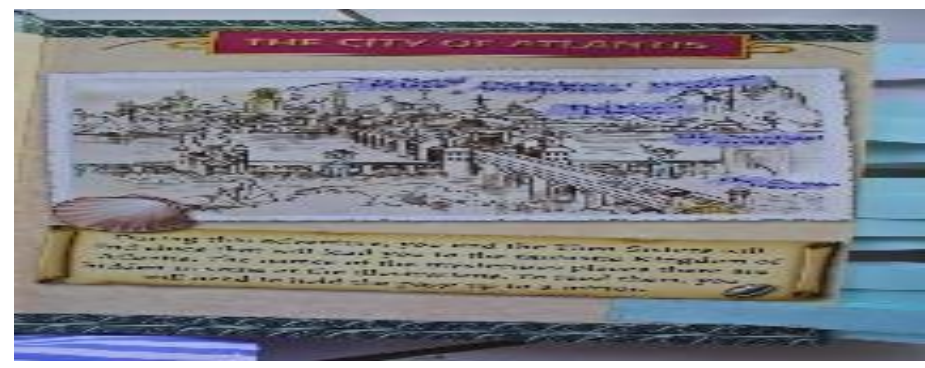

Figure 1. The City of Atlantis

By using the semiosis process, the picture of "The City of Atlantis" is understood as a sign. Peirce (1991) argues that sign can appear in many forms and a sign may be either simple or complex. He also defines no matter how complex, phenomenon may be viewed as a sign from the exposure it enters into a process of semiosis. In this analysis, the semiosis process included triadic relationship among sign or representamen, object, and interpretant. The representamen refers to a thing as a representative of another thing, that is its object. Before being interpreted, the representamen is purely called as a potentiality.

Based on this concept "Atlantis City" is representamen. The "Atlantis city" is an object. The reader or the observer could know "The Atlantis City" through the picture in which the author represents. The object refers to what is represented by the sign. The sign expresses information about the object, preparing it as an object in which the interpreter is already familiar by observation brought by other signs. For example, the picture of "The City of Atlantis" that is used as a datum 1 is identified as representamen) for "A city which name Atlantis". The buildings and it environments are identified as the object, since it is predicted that one already has insight to all information about this city from other characteristics. It can be from facilities and infrastructures, recreation area, government building, etc. The Atlantis city shows that the situation in the portray is a city as a central of government, and cultural center. Furthermore, the interpreter knows "a city of Altantis," then the sample gives the interpreter insight that this 
city of Atlantis is "greatness". To shorten, Peirce differs the object's dynamicity from the immediate object. Dynamicity refers to the object that is in reality and immediate object refers to the object as it is represented by the sign. In datum 1 example, the "City of Atlantis" is the dynamical object, and the brown and blue bright color (of the city picture) is the immediate object. After being interpreted, the representamen has the ability to produce an interpretant, which allowing the first one to refer to the object. For example, the definition of "a city of Atlantis" according to the author is 'King's city', because the author gives its explanation refers to the object (= what this city represents) and thereby allows the representamen (= the city of Atlantis) to refer to this object.

The picture "City of Atlantis" is representamen [R]. This picture is identified as icon. The analogy is the same as "someone's portrait" (sinsign) is the icon of that "person", the "City of Atlantis picture" is the icon of that "city. Consequently, the semiosis process for this data is that the representamen [R] is the portrait of remarked above, which perform the specifically buildings as object [O]. The term icon's diagram use in this analysis refers to 'An icon has a physical resemblance to the signified, the thing being represented.

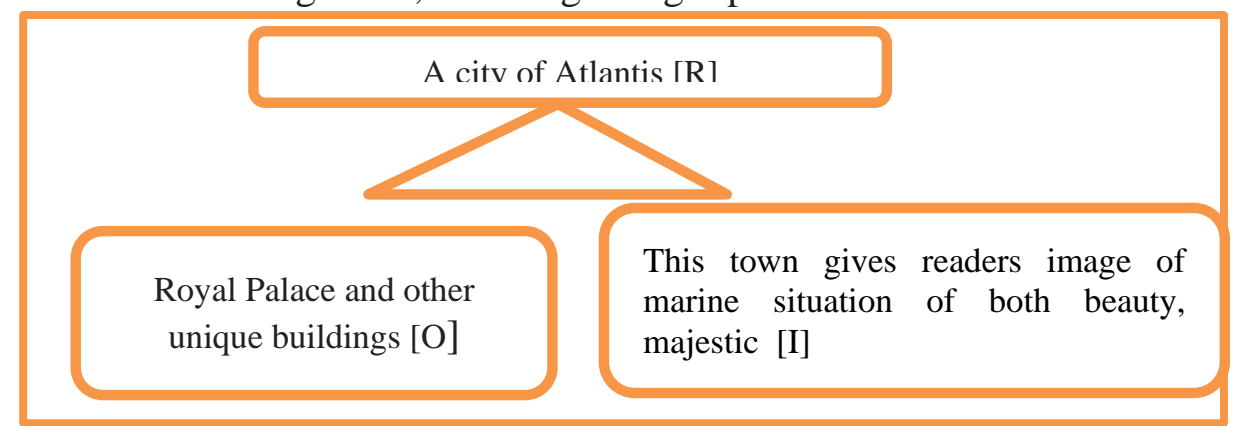

Diagram 1. Icon's Diagram of Datum 1: "The City of Atlantis"

The term or icon's in Diagram 1 of datum 1 refers to a sign that shows a natural relationship between signifié 'marked thing' and signifiant' the marking thing' or there is resemble between the signal 'thing which is marked' and the meaning. By using semiosis process, sign as an icon could divided into three categories. The procedure of semiosis process is such as follow:

\section{The First Trichotomy: The representamen}

representamen refers to (1) a qualisign (firstness). It is a quality that similarly functions to a sign; (2) a sinsign (secondness). It is a specific spatio-temporal thing or event that functions like a sign; or (3) a legisign (thirdness). It is a conventional sign. In data 1 as representamen refers to "the City of Atlantis" is the famous Royal Palace of architects. This palace was built by the Minoans, named for the legendary King Minos. It is believed to be the first great civilization from Europe as argued by Pruitt (2018). This meaning is obtained from a legisign or meaning a conventional sign, as Pruitt explained. From a specific spatio-temporal thing or sinsign meaning, this picture shows the replica or miniature of "Atlantis city" which is known as 'a wealthy modern city that has advanced technology." Representamen is seen from qualisign shows that 'the Atlantis city is big royal city' that "There is a palace of the Ten Kings, The Coral Hill, The Royal Library, The Nautical Garden and The Ocean Door".

\section{The Second Trichotomy: The Object}

Representament refers to firstness, secondness or thirdness of object by virtue. It is portrayed through relationships of contextuality, similarity, and contiguity 'being contacted with something' or 'law.' Accordingly, the sign is called an index, an icon, or a symbol respectively as argued by Peirce (1991). If the sign resembles the object, the reference between a sign and its object is iconic. An icon may perform as its representamen like a qualisign, legisign, or a 
sinsign. For example, "the City of Atlantis" or qualisign is created by a legend and an actual historical place invented by Plato written in his book entitled "Atlantis the Antediluvian World, 1882 as the icon of advance civilization (Pruitt 2018).

The Atlantis City's portrait as sinsign is the icon of 'a royal city', and The Royal Palace as sinsign is the icon of a place where the Atlantis Kings live. A drawing of an Ocean Door (sinsign) is the icon of 'door is also used to refer to a house or other building near the sea'. It functions as a replica of the legisign signifying 'marine situation' through iconic portrayal of a certain city that takes its part as a general 'marine city' as objects. If the sign really is affected by the object, the reference between a sign and its object is indexical. For example, the position of 'The Ten King Palace' in the center of city caused this city becomes famous and it is one of an exciting city. Each building is bordered with colorful mosaic tile, stones buildings scattered throughout the area with ceramic lizard, beautiful fountains and unique building structures are the index of a pleasant place, modern and high-level society.

A sign is considered as a symbol when, by virtue of law, it refers to its object. The City of Atlantis is identified as a symbol of 'society high civilization.' To determine this symbol, it is done in two ways: (1) the symbolic rule that is formulated a priori. It refers to correlation of knowledge which proceeds from theoretical deduction rather than from observation or experience by convention, (2) a posteriori. It means relating to knowledge which proceeds from experiences or observation to deduce the probability causes through cultural habit. Representament of a symbol is actually a legisign, yet it cannot actually act until it is formed in a replica. Accordingly, the symbol has implication to an index (Peirce 1991). It can be seen from traffic code where the red light is abstract symbol that belongs to symbolic legisign (conventional meaning) red light meaning is 'stop'. The same way is done to determine symbols "The City of Atlantis" as 'society with high civilization in the past'

\section{The Third Trichotomy: The Interpretant}

As the interpretant, the sign consists of (1) firstness called rheme; (2) a dicent sign or secondness; (3) an argument or reasoning or thirdness (Peirce, 1991). The rhematic interpretant has its firstness structure. In applying the relationship between the object and representament, it refers to the representament qualities. They are the qualities of a wholely possible objects. The rheme refers to equivalent of a variable in a functional proposition. It can be seen from a person's portrait represents a whole class of possible objects without any indications. It is the people who look like the portrait.

If the portrait is considered in a context, the level of interpretation changes. It is where it is accompanied by something indicating the person's name, It can be seen from a passport. The same way to interpret the image of "The City of Atlantis" with the context show that this town is exciting, marine, beauty, luxury, glory, nature, greatness. The function of this city is as the economic, cultural, social center. The dicisign refers to a sign which is interpreted at the secondness level. It functions as a logical proposition because it embodies a relationship between constants: a subject or what the material is about and a predicate or what one says about it. It is also either true or false. It can be seen from a person's portrait that indicates his name as a dicent indexical sinsign. The sign interpretant can be in the form of proposition that "the person performed in this picture is called Mr. Lee as a teacher". The same way to interpret portrait "The City" with an indication of its' name of Atlantis is a dicent indexical signsign. This city could be interpreted as town where the population has "high civilization". The argument refers to a sign that is interpreted at the thirdness level. It earns a formulation to the rule that joins the representamen to its object. Argument always has a symbol as its object and a legisign as its representamen. Three kinds of arguments are differentiated and it depends on the nature of the rule which binds the representamen to its object. The rule consists of (1) imposition on the facts such as "Every time there is a red light, there is an order to stop"; (2) a result of the facts such as induction: "there is smoke, there is fire"); or (3) the argument that may consist of formulation of 
a rule embodied by a hypothesis that would explain a fact called abduction. By using induction as a way to interpret the sign, it could be stated that the City of Atlantis is a symbol of the "lost town. Diagram 2 explains the relationship.

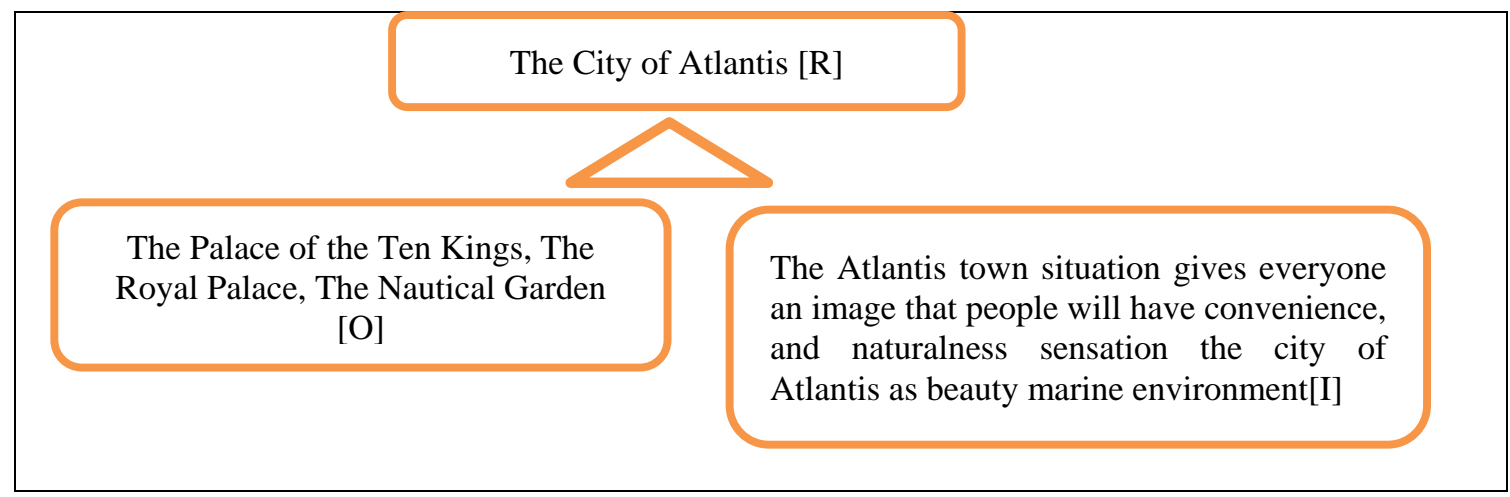

Diagram 2. Symbol's Diagram of Datum Analysis 1: "The City of Atlantis"

The basic conclusion for these two semiosis processes from the representamen aspect reveals that "the City of Atlantis" is the famous Royal Palace of architects. Looking at the object aspect, a picture the city of Atlantis is a big city which resembles a town of Atlantis Plato describes in his book "Atlantis the Antediluvian World, 1882. The Atlantis City's portrait is the icon of that 'a royal city', and The Royal Palace is the icon of 'a place where the Atlantis Kings live, this town situation gives everyone an image that people will have convenience, naturalness sensation the city of Atlantis as beauty marine environment'. A sign is a symbol The City of Atlantis is identified as a symbol of 'society high civilization.' By using induction as a way to interpret the sign, it could be formulated that the City of Atlantis is a symbol of the "lost town."

\section{Verbal Symbol Form}

The form of the symbol described in this description consists of words and onomatopoeia. Both are identified as verbal symbol. In this connection, in this section the identification of verbal symbols is found in "The City of Atlantis" is presented sequentially through words, onomatopoeia. The following is an explanation of the elements of the verbal symbol form. In some sense, "symbol" is interpreted as follows: symbol is something that is usually visible that it replaces an idea or object. Symbols are words, signs or signs, which are used to represent something else such as quality, meaning, ideas, abstraction, and objects. This concept is used to analyze such as follow:

Words

In the context of "The City of Atlantis" many words are identified as symbols, such as: mouselets 'A small or young mouse', it is a symbol of shyness, meekness, cleverness, deftness. Tornado 'A person or non-person creature characterized by devastating action or violent or emotion'. It is a symbol of 'people who move quickly in helping others.'

\section{Onomatopoeia}

In transferring his idea author often uses onomatopoeia to produce utterance differ. To identify onomatopoeia, this study uses Brendin (2016: 558) as cited by (Karina 2017:10) such as direct onomatopoeia. It refers to a word that similarity resembles the sound of the object. For example: the word huff means 'blowing out air loudly on account of exertion'. Huff is associated with 'someone expresses his feeling of petty annoyance'. The word puff means 'move through the air in short burst'. Puff is associated with 'Be conceited, proud of.' The word click means 'become suddenly clear or understandable'. It is associated with become friendly. These words are identified as direct onomatopoeia. 


\section{Non-verbal Symbol Form}

Non-verbal symbols in this analysis are symbols that originate from "The City of Atlantis" which is used as communication in conveying messages. Consequently, in this section the identification of nonverbal symbols is found in "The Journey to Atlantis" is presented sequentially through picture and color. The following is an explanation of the elements of the nonverbal symbol form.

\section{Picture in Picture Books}

Picture in picture books are significant and accessible that they are visual art for children because the picture books offer opportunities among other children to make connections to values, personal experience, and beliefs of both families and communities (Mantei \& Kervin, 2014). He also describes that picture books are crucial and useable form of visual art for children because there are several aspects such as: how to make connections to other person, how to express our experiences and how to understand beliefs and values within families and communities (Mantei \& Kervin, 2014). To analyze picture (Mantei and Kervin 2014) suggest several dimensions such as: format of picture, content of picture, line, shape, and color. The following is an explanation of the elements of the picture form.

The format picture in Figure 4 in little boxes it is not real "photograph," but it is only a mimetic painting the city of Atlantis. This illustration "The city of Atlantis" enhances the story. The weather in this picture convey good mood. There are four kinds of line, such as: a) vertical line indicate stability, height, separates element in image; b) horizontal lines can be interpreted as bring elements together, calming; c) diagonal lines is interpreted as suggest motion and movement; and d) thin lines: suggest softness, an elegant quality. It shows a quick synopsis of the story through image visualization. Based on its story, this image tells about a big and modern town with high technology. It shows the expression of beautiful city which is identified through architecture and art. They are history and culture, and water views and mountain vistas. It is known at that time as a political and cultural center.

\section{Color}

The color of purple, for instance, is associated or interpreted with royalty which symbolizes nobility, power, ambition, and luxury. Purple are also associated with dignity, wisdom, creativity, independence, mystery, and magic Purple is associated with dignity, wisdom, creativity, independence, magic, and mystery. The brown color means stability or the fantastic kingdom situation.

In brief, the meaning of verbal and non-verbal symbol on text and picture is the most famous emperor Atlantis is a city, possibly the vast majority of people, even a little familiar with the history and culture of Atlantis, knows the name. Atlantis is known as one of the most beautiful cities in the world. There are many monuments of architecture that many have heard and visited possible.

\section{CONCLUSIONS}

Based on semiosis processes focus on the research question number (1) and the analysis, the writer found 40 identified icon and 16 environment symbols (reference to Peirce's semiotic theory). From 16 environment's symbols' in 8 environment pictures have been selected by doing random sampling data from number 1-8. The writer found that the picture of environment's symbols gave the first outcome to the writer in receiving the meaning of the verbal symbol (narration text) nonverbal symbol (picture and color). These symbols give a clue for obtaining the meaning of environment symbol of Atlantis.

Referring to the meaning of verbal and nonverbal symbol focus on 2.1 the research questions number two and the analysis, the writer found the verbal meaning of thirty-six or (36) onomatopoeias. They are identified as direct onomatopoeias, like huff, boo, click, tick tock, this kind of onomatopoeia refers to a word that similarity resembles the sound of the object. Further, the nonverbal analysis on picture, the writer found forty, or (40) pictures describe the Atlantis 
environments, and eighteen (18) colors, such as yellow, yellow green, green, blue, bright-blue, deep blue, blue-green, blue-violet, violet, red, red-orange, orange, pink, yellow orange, black, grey, and white.

\section{REFERENCES}

Ajayi, V.O. (2017). Primary Sources of Data and Secondary Sources of Data. 1-6.

Bianquin, N. \& Sacchi, F. (2017). More than Just Pictures: Using Picture Books to Broaden Young Learners' Disability Understanding." Proceedings 1(9):890.

Buchler, J. (2006). The philosophy of Peirce: Selected writings. The New England Quarterly 14(3):601-612.

Calero, H. H. (2005). The Power of Nonverbal Communication How You Act Is More Important Than What You Say. Los Angles: Silver Lake Publishing.

Callow, J. (2018). Classroom assessment and picture books - Strategies for assessing how students interpret multimodal texts." Australian Journal of Language and Literacy 41(1):520 .

Chandler, D. (2006). Semiotics the Basics, Second Edition. Second. New York: Routledge.

Damy, E. (2012). The Journey to Atlantis. New York: Scholastic.

Hidayat, R. S. 1988. Pengantar Linguistik Umum. edited by H. Kridalkasana. Yogyakarta.

Karina, M. D. (2017). English onomatopoeia in children books." Sanata Dharma.van Kraayenoord, Kraayenoord, and S. Paris. 1996. "Story Construction from a Picturebook: An Assesment Activity for Young Learners." Early Childhood Research Quarterly. 11(2). 4161.

Liszka, J. J. (2012). A General Introduction to the Semeiotic of Charles Sanders Peirce. Bloomington: Indiana University Press.

Mantei, J, \& Kervin, L. (2014). Interpreting the images in a picture book: Students make connections to themselves, their lives and experiences English Teaching Practice and Critique 13(2).76-92.

Mushodiq, M. A. (2018). Tanda peircian dan maknanya dalam unsur intrinsik cerpen "IndamaYa'ti Al-Masa Karya Naguib Mahfouz". Jurnal Lingua. 13(1).

Nöth, W. (2011). The criterion of habit in Peirce's definitions of the symbol. Transactions of the Charles S. Peirce Society. 46(1). 82-90.

Ozsezer, M. Bulut, S., \& Canbazoglu. (2018). Picture in children's story books: Children's perspective. International Journal of Educational Methodology. 4(4).103-115.

Pearson, D. (1993). Teaching and learning reading: Reasearch perspective. Language Art. 70(2). 02-11.

Peirce, C. (1991). Logic as Semiotic. The Theory of Sign. London: Cambridge University Press.

Pettersson, S. (2000). Graphic Symbols Design and Meaning. in Griffin, W. J. Gibbs, \& V.S. Williams (Eds.

Pruitt, Sarah. (2018). "The Top Thoeries of Atlantis.” Civilization.

Yu, Hailing, and Song, Z.. (2017). Picture-text congruence in translation: Images of the zen master on book covers and in verbal texts. Routledge Taylor and Francis Group. 27(5). 604-623,. 